\title{
OBJECTIVE AND SUBJECTIVE DETERMINANTS OF PROSPECTIVE RESIDENTIAL MOBILITY
}

(Received 30 March, 1975)

\begin{abstract}
The increasing interest in subjective as well as objective measures of wellbeing raises the issue of the relative importance of these two different types of measures when they are included as independent variables in analytical or predictive models. In the research reported here, survey data are used to evaluate the relative importance of objective and subjective indicators in providing an understanding of why households desire to move. Overall, it is found that subjective indicators add considerably to the explanation of mobility inclinations over and above that contributed by objective indicators. A comparison of explanatory powers for the full sets of objective and subjective predictors within two length of residence subgroups indicates some interesting differences, however. Objective and subjective predictors are close in explanatory power for longer-term residents, while subjective measures are considerably more important for shorter-term residents.
\end{abstract}

\section{BACKGROUND}

Over the past several years, there has been increased interest among social scientists in collecting 'social indicators' of the quality of life. These indicators are intended to parallel, but more importantly, to supplement economic indicators which have been widely used to gauge the state of an economy. The skepticism with which economic indicators have been viewed as accurate reflectors of a country's welfare has, in part, generated this increased interest in social indicators. One American sociologist has noted that despite an unprecedented rise in our GNP over the last 5 or 10 years, it would take a brave man to argue that the quality of our lives have risen proportionately. (Campbell, 1971.)

A distinction can be made between two major types of social indicators: objective social indicators and subjective social indicators. Objective indicators are, for the most part, straightforward definitions of various phenomena. Birth rates, absenteeism from work, and housing type are examples of objective measures. Subjective indicators are designed to assess people's satisfaction with various facets of their lives such as their satisfaction with family, work and house. 
A good deal of convincing evidence has and continues to be amassed concerning the incompleteness of objectively measured phenomena alone as indicators of well-being and quality of life (Campbell and Converse, 1972; Robinson, 1973; Marans and Rodgers, 1974; Newman, 1974). For this reason, subjective measures of attitudes, perceptions and assessments are also being collected and studied. The argument for their collection and analysis appears to be a clear and persuasive one: an individual's feeling of well-being is best understood when information about both the objective characteristics of his situation and his perceptions of these characteristics are examined. In studying residential location decisions of households, for example, it is important to know how much a respondent pays in housing costs in relation to his income. It is at least equally important, however, to know whether he views these payments as high or low relative to what he is actually receiving in terms of housing service.

To be sure, the differentiation between the two types of variables is a relative one, and is based on the degree to which personal judgement and evaluation influence responses. In addition, the conceptual and motivational origins of personal assessments and judgements are not obvious. Some have suggested that subjective assessments connote some standard against which one judges one's own situation (Withey, forthcoming). Comparisons between what one now possesses and what one expects or aspires to, as well as what one thinks is just or equitable, is also suggested by subjective evaluations.

One important issue raised by this conceptual approach to studying quality of life indicators is the relative importance of these two different groups of measures when they are included as independent variable in analytical or predictive models. Stated most simply, do subjective measures add anything to objective ones in understanding behavior? This paper will report on a comparative analysis of a set of objective measures and a set of subjective measures in a study of prospective residential mobility (i.e. the desire to move). In particular, we will assess the relative importance of groups of variables which measure the objective characteristics and subjective perceptions of the house, neighborhood and community environments (or the 'residential environment') in providing an understanding of prospective residential shifts. ${ }^{1}$

The study of anticipatory mobility can provide useful information about the demand component of household residential location decisions 
by indicating which factors are associated with the desire to change residences and which factors are linked to satisfaction with remaining in the present residential environment. ${ }^{2}$

It is expected that in the majority of cases, subjective indicators will help to clarify the relationship between objective indicators and the criterion variable, the desire to move (Rossi, 1955, p. 70). If, as other research has suggested, decisions about residential mobility center primarily on the household's perception of how well the present residential setting meets its needs and preferences, then the more directly and specifically we measure these social psychological factors, the better should be our ability to account for and predict mobility desires (Foote et al., 1960; Rossi, 1955).

The data upon which this analysis is based were collected in 1971 as part of a national survey of the Quality of Life in America. In contrast to much previous mobility research in which single communities or special subgroups within the population have been studied, this data provides information on an unbiased representative sample of more than 2000 households across the nation.

\section{THE CONCEPTUAL SCHEME}

\section{A. The Predictors}

In Table I, the sets of objective and subjective predictors used in the analysis, in addition to background factors, are listed. Both the objective and subjective predictors include variables which relate to the environmental settings of the house, neighborhood and community. Thus, for example, objective predictors include variables characterizing the house environment, such as degree of crowding, type of dwelling unit and rent or value to income ratio, and the neighborhood and community environment, such as the size of the geographic area in which the respondent lives. Subjective predictors, on the other hand, include house environment variables, such as the evaluation of dwelling unit costs and the size of rooms in the house, and measures of the neighborhood and community environments, such as the evaluation of neighbors. ${ }^{3}$

\section{B. The Desire to Move and Length of Residence}

The findings of past research indicate, in a general way, that the length of 


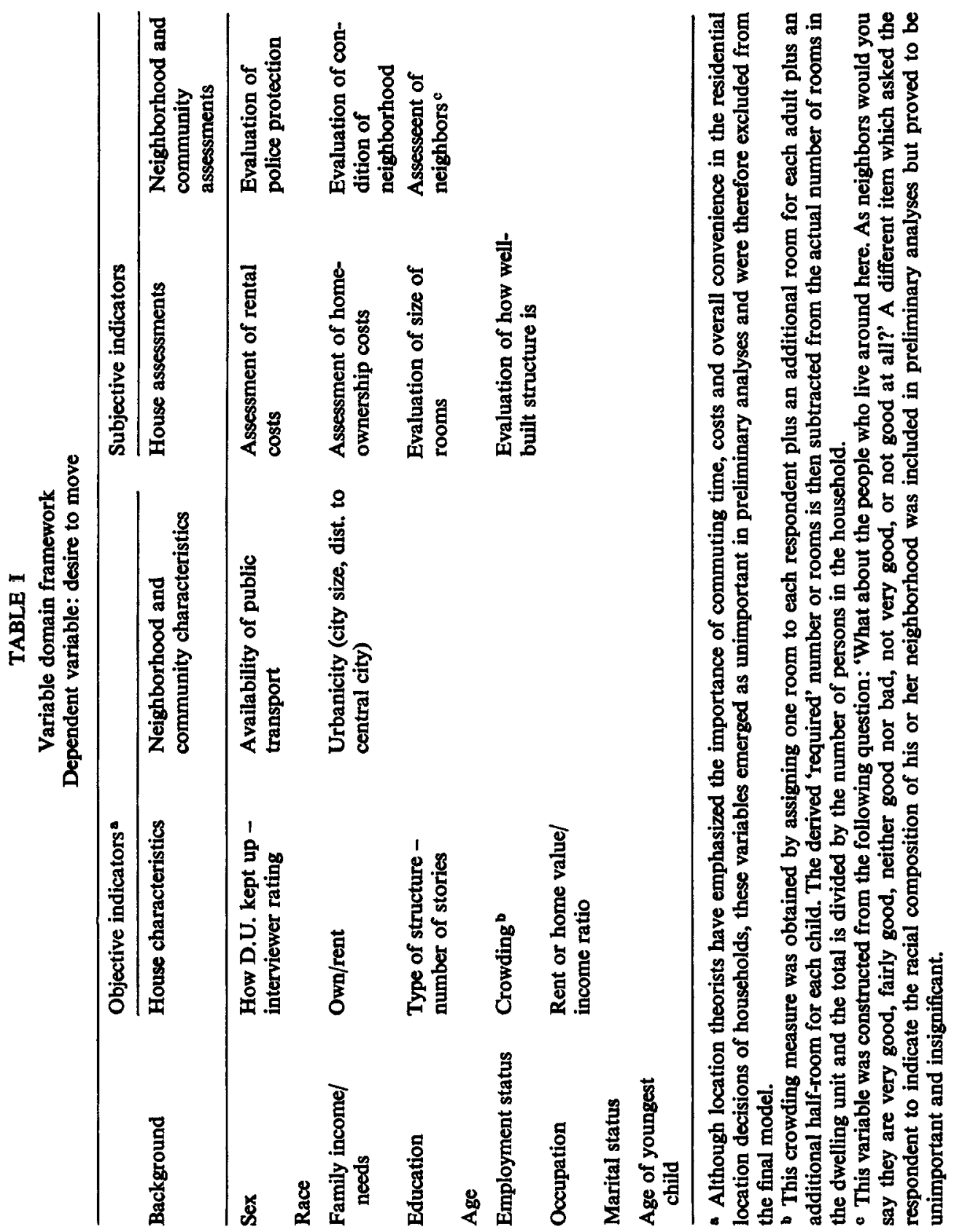


time a person lives in one residence has a considerable effect on his or her prospective or actual mobility. Many sociological studies, for example, have noted that length of residence is closely correlated with 'commitment' to a particular residential location. Sinply stated, the longer a person lives in one dwelling unit and, therefore, within one area, the more likely (s)he may be to have developed close local ties and friendships and a feeling of identification with the area. Hence, a sense of commitment to the location of residence is associated with the long term duration of that residence and has implied a smaller likelihood of desiring to move.

The Quality of Life data indicate that shorter-term residents are younger than longer-term residents, are more likely to live in some form of multiple dwelling (and, therefore, to be renters more often than owners) and to have a young child at home. Shorter-term residents also appear to suffer more than their counterparts from crowding within the dwelling unit.

These considerations argue for the inclusion of a length of residence variable as one among several predictors in an additive regression model. While this analytical approach can provide information on the relative importance of length of residence on prospective mobility, it is not designed to deal adequately with the possibility of interactions between classes of other predictors on the desire to move for different length of residence groups. There are several reasons to suspect that the effect of subjective and objective predictors on the desire to move may depend upon the length of residence. Families of shorter-term residents are in early life cycle stages, are often still expanding, and are most likely to have housing needs that are out of balance with their actual housing (Rossi, 1955 , p. 72). Thus, although it will be important to account for the objective characteristics of the present housing situation of shorter-term residents, such as the degree of crowding within the dwelling unit and the tenure status of the household, it will be even more important to account for the manner in which the household regards its place of residence in terms of size, quality, attractiveness, and so on. It is this latter set of variables which describes the ways in which actual housing is not meeting the needs of these families and why a change of residence is desired.

For the longer-term residents, however, both the commitment to a particular house, denoted by the high incidence of homeownership among this household group, and the long-term nature of that commitment, evidenced by the length of residence in one dwelling unit, suggest that 
these families are currently living in housing which, by and large, meets its needs. ${ }^{4}$ To the extent that subjective indicators reflect how people regard their own situation relative to that of others or to what they demand, expect, or aspire to in the future, it is hypothesized that these measures will add less to our understanding of the mobility anticipations of longer-term residents over and above that accounted for by objective indicators.

Because one of the goals of this paper is to ascertain whether in fact such interactions exist, we will stratify the full sample on the length of residence variable and then examine the relative importance of predictors and groups of predictors within the two sub-groups or partitions. Thus, subsequent analyses are performed separately on 'shorter-term' and 'longer-term' residents. ${ }^{5}$

\section{ANALYSIS AND RESULTS}

Our procedures are first, to examine the relationship between individual independent variables for the sets of objective and subjective predictors for each of the two length of residence groups and second, to estimate the extent to which the entire set of objective predictors explains moving decisions over and above subjective and background predictors, and similarly to estimate the extent to which the set of subjective predictors explains moving desires over and above objective characteristics and background factors.

For these analyses, a dichotomous dependent variable was constructed from the questionnaire item asking respondents whether they desire to move or if they are satisfied to stay (in their present location). Thus, the dependent variable assumes a value of one if the respondent desired to move, a zero if not. Variables describing the social and demographic characteristics of the respondents were also included in these analyses so that the effects of each variable and the differences in explanatory power between variables could be studied without concern for the possibility that these effects might result from intercorrelations with the background factors.

The results of the full regression (listed in Appendix Table III) in which all of the component variables are analyzed simultaneously indicate that for longer-term residents, the explanatory power of particular objective 
indicators, namely urbanicity, age of household head and home ownership, have a significant relationship with the desire to move, while the beta coefficients for the subjective indicators are considerably lower. For shorter-term residents, however, it is the subjective indicators, such as the assessment of room size and how well built the structure is, which explain the greatest proportion of variation in prospective mobility.

Although this procedure is appropriate for estimating the relative importance of individual predictors in explaining the variation in the dependent variable, it is not designed to provide information on the relative usefulness of a group of predictors. Since we are interested in the relative importance of the set of objective indicators and the set of subjective indicators, it is necessary to use a statistical measure which is appropriate for estimating the relative importance of a group of variables - the partial $R$ square. (Andrews et al., 1973).

Accordingly, we will again use multiple regression to estimate: (a) the proportion of variance in the desire to move which is accounted for by the set of objective predictors over and above that accounted for by the subjective predictors and background factors, and (b) the proportion of variance in the desire to move which is accounted for by the set of subjective predictors over and above that accounted for by the objective predictors and background factors. These proportions will then be compared in order to determine the relative importance of these two groups of predictors for longer-term and shorter-term residents.

Table II shows, for both household groups, the partial $R$ squares $^{6}$ of the set of objective predictors and the set of subjective predictors. The size of each partial $R$ square indicates that subjective indicators explain variations in mobility desires for the two household groups over and above that accounted for by objective indicators, and vice versa. Thus, both objective and subjective predictors account for a substantial proportion of the unexplained variance in the desire to move. Differences in relative importance of the measures for shorter- and longer-term residents do, however, exist. When the partial $R$ squares of the two different sets of predictors are compared for shorter-term residents, subjective assessments of the residential environment emerge as substantially more important ( 0.10 versus 0.05 ) in predicting the desire to move. For longer-term residents, on the other hand, there is very little difference $(0.08$ versus 0.07$)$ between the power of variables describing the objective characteristics of 
environmental settings and variables describing the respondents' subjective assessments of those settings. The differing importance of expectations for future housing consumption for the two household groups hypothesized above may account for the differential effects of objective and subjective indicators on the mobility desires of each group of households. Because, on the whole, shorter-term residents are at earlier stages in the life cycle and are still residentially mobile, it is likely that they are some distance away from what might be considered their 'ideal' housing purchase. On the other hand, longer-term residents are probably much

TABLE II

Relative importance of objective characteristics and subjective assessments in predicting the desire to move for Shorter- and Longer-term residents

\begin{tabular}{lll}
\hline Variable groups & $\begin{array}{l}\text { Shorter-term } \\
\text { partial } R^{2}\end{array}$ & $\begin{array}{l}\text { Longer-term } \\
\text { partial } R^{2}\end{array}$ \\
\hline $\begin{array}{l}\text { Objective characteristics of the house, } \\
\text { neighborhood and community } \\
\text { environments }\end{array}$ & 0.05 & 0.07 \\
$\begin{array}{l}\text { Subjective assessments of the house, } \\
\text { neighborhood and community } \\
\text { environments }\end{array}$ & 0.10 & 0.08 \\
$\begin{array}{l}\text { Number of observations } \\
\text { number }\end{array}$ & $\begin{array}{l}1447 \\
(\vec{Y}=31.7)\end{array}$ & $\begin{array}{l}690 \\
(\vec{Y}=18.8)\end{array}$ \\
\hline
\end{tabular}

all results are significant at the 0.01 level.

closer to the consumption of a house that meets their needs, if they do not already live in one. Simply stated, the current residential environment of longer-term residents may be almost congruent to their expected residential environment. If, as suggested earlier, subjective variables measure, at least in part, the adequacy of what one now has as compared to what one expects to have in the future, it should not be surprising that the difference between objective and subjective predictors is very small for longer-term residents and much larger for shorter-term residents. Thus, subjective assessments of the house, neighborhood, and community environments have a greater effect on the prospective mobility of shorter-term as compared with longer-term residents. 


\section{SUMMARY}

The research reported here has used data from survey research to evaluate the relative importance of objective and subjective indicators in providing an understanding of why households desire to move. Broadly speaking, it is found that, indeed, subjective indicators are relatively more important than objective indicators in this regard. Perhaps even more noteworthy is the observation that subjective indicators add considerably to the explanation of mobility inclinations over and above that contributed by objective indicators.

However, when the sets of objective and subjective predictors are compared for the shorter-term and longer-term residents sub-groups, the importance of subjective variables over objective measures was not maintained for both groups. In the case of longer-term residents, objective and subjective predictors were virtually identical in their explanatory capabilities, while for shorter-term residents, subjective measures were superior. This finding suggests that the effect of the set of objective and the set of subjective variables on the desire to move depends upon length of residence. The interpretation offered for this differential importance focused on the role of expectations and aspirations in the conceptual foundations of subjective measures.

\section{APPENDIX}

TABLE III

Relative importance of background, objective characteristics and subjective assessments of the house, neighborhood and community environments in predicting the desire to move of shorter- and longer-term residents ${ }^{*}$

\begin{tabular}{|c|c|c|c|}
\hline \multicolumn{2}{|l|}{ Shorter term } & \multicolumn{2}{|l|}{ Longer term } \\
\hline Variable & $\begin{array}{l}\text { Beta } \\
\text { coefficients }\end{array}$ & Variable & $\begin{array}{l}\text { Beta } \\
\text { coefficients }\end{array}$ \\
\hline $\begin{array}{l}\text { Size of rooms } \\
\text { Well-built }{ }^{b} \\
\text { Crowding } \\
\text { Whether own }^{\text {b }} \\
\text { Whether young child b } \\
\text { Cost assessment } \\
\text { Age }\end{array}$ & $\begin{array}{r}0.19 \\
-0.14 \\
-0.10 \\
-0.10 \\
0.11 \\
0.07 \\
-0.09\end{array}$ & $\begin{array}{l}\text { Urbanicity }{ }^{b} \\
\text { Well-built }^{\mathrm{b}} \\
\text { Age }^{\mathrm{c}} \\
\text { Whether own }^{\mathrm{b}} \\
\text { Cost assessment } \\
\text { Size of rooms } \\
\text { Condition of houses in } \\
\text { neighborhood }\end{array}$ & $\begin{array}{r}-0.24 \\
-0.15 \\
-0.13 \\
-0.13 \\
0.12 \\
0.12 \\
-0.10\end{array}$ \\
\hline
\end{tabular}


Table III (continued)

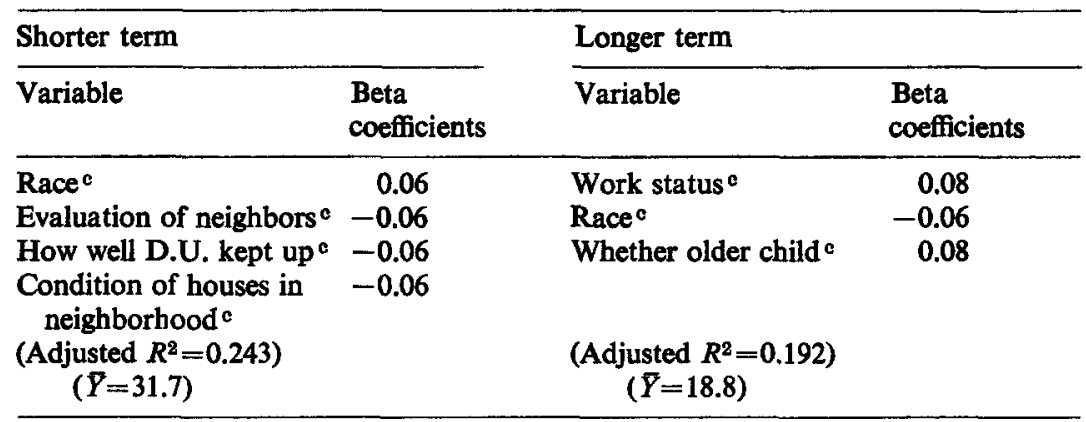

- Only predictors significant at or beyond the 0.05 level are listed.

b Significant at 0.01 level.

c Significant at 0.05 level.

\section{Institute for Social Research \\ University of Michigan}

\section{NOTES}

1 There is substantial evidence that the largest proportion of residential mobility stems from some source other than either the addition of new households to the population or job shifts. It seems reasonable that characteristics and assessments of the house, neighborhood and community environments in which people reside may account for some of the "unexplained' population movement or prospective movement.

2 There is evidence that the statement of a desire, intention, plan or expectation of moving is a good indicator of actual mobility. (There are some differences between these concepts but they are not critical for the current argument). In his comprehensive study of prospective and retrospective mobility, Rossi (1955) stated that: "... the actual behavior of the families interviewed conforms closely with their verbalized desires and intentions". In addition, it has been estimated that about 20 percent of the United States civilian population actually moves each year (Foote et al., 1960). In the Quality of Life study, about 27 percent of respondents reported their desire to move. Of course, not all people who actually move report a desire to move; thus, these two population groups are not entirely comparable. Some very recent estimates are, however, available on the actual mobility of families who previously reported the expectation of moving (Duncan and Newman, forthcoming). This research indicates that somewhat less than half of families reporting the expectation of a voluntary move in 1970 actually moved in the subsequent thre years.

3 To be sure, the subjective variables are not strict counterparts of the objective variables. In part, this lack of correspondence results from preliminary search analyses in which the most important predictors in terms of variance explained were retained for further study while less important predictors were eliminated. Because the primary goal of the analysis is to determine the relative importance of subjective versus objective variables in explaining the desire to move, those variables with the greatest chance of success are included in the analysis. 
4 Because longer-term residents tend to be in later stages of the life cycle (for example, their mean age is 55) and to have grown children who no longer live in the house, we might expect these households to be somewhat 'overhoused' and to desire to move to reduce their excess housing space. Past research indicates, however, that older, longterm homeowners have a marked preference to remain in their homes and that excess space within a dwelling unit has a relatively small effect on mobility inclinations as compared with inadequate housing space.

5 A multivariate search technique known as the Automatic Interaction Detector was used to specify the number of years which best distinguishes longer-term residents from shorter-term residents as per their relationship to the desire to move (Sonquist, et al., 1971). Interestingly, the best dividing line occurs at 11 years and results in 1447 shorterterm residents and 690 longer-term residents. Unfortunately, more complete discussion of this result is beyond the scope of this paper. The occurrence of this split at a point in time far beyond that used in past studies, however, seems to indicate that a much longer tenure in one dwelling unit is requireo for developing a very strong commitment to remaining in a particular residential environment.

- The partial $R$ square measures the explanatory power added by a predictor or set of predictors over and above all other precictors. It is a measure of the importance of a predictor or group of predictors.

\section{BIBLIOGRAPHY}

Andrews, Frank M. et al.: 1973, Multiple Classification Analysis, Institute for Social Research, Ann Arbor, Michigan.

Campbell, A.: 1971, 'Social Accounting in the 1970's', Michigan Business Review XXIII, 2-8.

Campbell, A. and Converse, P.: 1972, The Human Meaning of Social Change, Russell Sage Foundation, New York.

Duncan, Greg and Newman, Sandra: (forthcoming), 'People as Planners: The Role of Expectations in Prospective Residential Mobility'; J. Morgan (ed.), Five Thousand American Families - Patterns of Economic Progress, Vol. III, Survey Research Center, Ann Arbor, Michigan.

Foote, N. et al.: 1960, Housing Choices and Housing Constraints, McGraw Hill, New York.

Marans, R. and Rodgers, W.: 1974, 'Toward an Understanding of Community Satisfaction'; A. Hawley and V. Rock (eds.), Urbanization - The State of Knowledge, National Academy of Sciences, Washington, D.C.

Newman, S.: 1974, The Residential Environment and the Desire to Move, Institute for Social Research, Ann Arbor, Michigan.

Robinson, J.: 1973, 'Measures of the Quality of Urban Life', Paper presented at Conference on the City in History, Ann Arbor, Michigan.

Rossi, P.: 1955, Why Families Move, The Free Press, Glencoe.

Sonquist, J. et al.: 1971, Searching for Structure, Institute for Social Research, Ann Arbor, Michigan.

Withey, S.: (forthcoming), 'Values and Social Change', B. Strumpel (ed.), Subjective Elements of Well Being, OECD, Paris. 